\title{
Brazilian Oral Research: Where is it headed?
}

Célio Percinoto

President of the $\mathrm{SBPqO}$ $\mathrm{t}$ is a known fact that Brazilian oral research has gained much greater vis-

ibility in the last decade, not only domestically, but also internationally, in well-reputed journals.

In Latin America, Brazil ranks first in the number of articles published, accounting for $2 \%$ of world scientific production. This is a very significant statistic, especially considering that it published more in the last decade than countries like Denmark, Austria, Belgium and Norway, which are countries with recognized technical and scientific development achieved over a long period of time.

Once this good news has been celebrated in terms of greater published volume, it is important that we reflect on the impact - or quality - of what is being produced. We should ask to what extent the published research has brought about practical improvement of the different sectors of society. The scientific community cannot evade this issue, and all of its members must get involved.

Brazilian oral research must achieve greater maturity, and this coming of age means, among other issues, focusing on addressing the actual needs of society. This is a natural process already experienced by many science-producing countries. It is not, however, a simple process, and requires the active participation of those who are most interested in achieving results, namely society and the community responsible for producing knowledge. Only in this way can we secure the engagement of an important ally for the development of Brazilian science, the Brazilian private sector and its financial support.

Today, our research is massively supported by government agencies, and only a small portion of it receives private funds. The small number of patent deposits submitted by Brazilian researchers is no doubt a result of this situation. Investments by the private sector are known to be contingent, among other things, on the production of palpable improvement for all, but this does not always occur when research is funded by the government.

Universities, which have always been aware of their mission, play a decisive role through undergraduate and graduate programs, in addition to providing the country with thinking minds.

In the ideal cycle of Brazilian Science, undergraduate students participate in scientific initiation programs and later in consistent graduate programs, thus qualifying them to participate in research groups and international cooperation programs, and ultimately helping to build the critical mass of professionals required to carry on the research profession. This cycle can only become dynamic when we achieve quality primary and middle education, thus laying a foundation of citizens with ethical principles. Hence, the path that Brazilian oral science should take will necessarily be paved by investments in human beings, giving it the structure needed for its intended purpose. Otherwise, we will not be able to be build science on solid ground.

So let's get down to business! 